\title{
Acute Placental Infarction
}

National Cancer Institute

\section{Source}

National Cancer Institute. Acute Placental Infarction. NCI Thesaurus. Code C117320.

A focus of necrotic placental parenchyma with clearly visible outlines of necrotic villous structures and absence of any hyalinization and fibrosis, which is frequently 1-2 days of duration. 